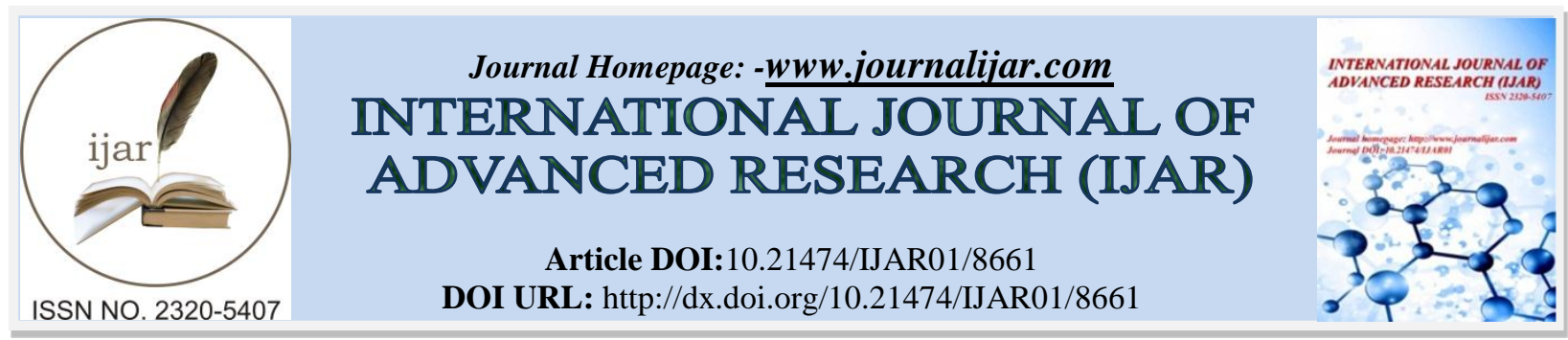

RESEARCH ARTICLE

\title{
INFLUENCE OF MANAVALAKALAI AND MEDITATION FOR VISIONARY PROBLEMS ON MIDDLE AGE WOMEN.
}

\section{N. Devi M Phil ${ }^{1}$ and G.R. Valliammal ${ }^{1}$.}

1. PhD Scholar, Bharathiar University, Coimbatore.

2. M Com., MA. MBA., PhD.,Asst. Professor, Department of Yoga for Human Excellence WCSC Vision, SKY Research Centre, Aliyar ,Pollachi.

\section{Manuscript Info}

\section{Manuscript History}

Received: 09 January 2019

Final Accepted: 11 February 2019

Published: March 2019

Key words:-

Eyesight, Meditation, Manavalakalai, Visionary.

\begin{abstract}
This study was conducted to view the influence of Manavalakalai and meditation for the middle age women who are having the visionary problems.

Methodology: For the study, 45 women with visionary problem from in and around Coimbatore were selected as subjects. The age of them ranged between 35 to 45 years. The subjects have been divided into three groups each consisting of 15 members. Experimental Group I went on Manavalakalai training; Experimental Group II went on only eye exercise for 8 weeks. Control Group were not given any kind of practices.

Results: The study showed a significant improvement in the vision of the Experimental groups I, II subjects than the Control group. The eye problems and blurry eyesight of the subjects got reduced without controlling their life style, food habits etc.

Conclusion: It has been concluded that Manavalakalai helps in improving the eye sight on middle age, reduce the eye sight problems and help the subjects to maintain their vision.
\end{abstract}

Copy Right, IJAR, 2019,. All rights reserved.

\section{Introduction:-}

The science of yoga begins to work on the outermost aspect of the personality, the physical body, which for the most people is practical and familiar starting point. When imbalance is experienced at this level, the organs, muscles and nerves no longer function in harmony, rather they act in opposition to each other. For instance, the endocrine system might become irregular and the efficiency of the nervous system decrease to such an extent that disease will manifest. Yoga aims at bringing the different bodily functions into perfect coordination so that they work for the good of the whole body. From the physical body, yoga moves on to the mental and emotional levels, many people suffer from phobias and neuroses as result of he stresses and interactions of everyday living. Yoga cannot provide a cure for life but it does present a proven method for coping with it.

\section{Objectives Of The Study}

This study was conducted to view the influence of Manavalakalai and meditation for visionary problems among middle age women which intently improves their health. 


\section{Statement Of The Problem}

The care taken as per their own objectives largely affect, mould and reflect the health. Lack of physical exercise which will supports the quality of wellbeing of every individual. The positive manner of physical exercise which correct them and guide throughout life.

\section{Hypothesis}

There was a significant difference in the vision (eyesight) variable in-between Manavalakalai and Meditation than the Control group.

\section{Limitations}

1. Economic and cultural status were not considered.

2. The factors like heredity, environment, climatic condition etc., were not consider.

3. The nutrients, food habits taken into consideration.

4. The working period, life style, sleep etc., were not controlled.

5. Daily routine works were not taken in to the count.

\section{Significance Of The Study}

1. The exercise doesn't harm any part of the body.

2. This study would create awareness about the efficiency of Manavalakalai on maintaining our physical health.

3. This study would create awareness about visionary among general public.

4. Blood circulation, heat circulation, respiration and all systems become normal effectively these exercises prevent diseases.

5. Inner organs also get the benefit of exercises.

6. Starting from the age of eight anybody can do this exercise.

7. Men, women, boys and girls all can practice these exercises.

\section{Selection Of The Subjects}

For the study 45 women with visionary problem from Coimbatore district were selected as subjects. They age range between 35 to 45 years. The subjects were divided into three groups each consisting of equal members. Experimental Group I went on Manavalakalai training; Experimental Group II went on eye exercise only for 8 weeks for 5 days in a week. Control Group were not given any kind of trainings.

\section{Selection of variables:}

Independent variables

Yoga practices of

1. Simplified physical exercises

2. Meditation

\section{Trainig schedule:}

\section{Manavalakalai contains}

1. Hand Exercise

2. Leg Exercise

3. Neuro muscular Breathing Exercises

4. Eye Exercise

5. Kapalabathi

6. Makarasana

7. Massage

8. Acupressure

9. Relaxation

\section{Meditation}

1. Agna Meditation

2. Shanthi Meditation

3. Thuriyam Meditation 


\section{Freiburg visual acuity rate:}

For statistical analysis the data collected from the pre-test and the post test on visual acuity rate of experimental groups and control group have been presented in Table I

Table I:-Analysis of Covariance for the pre and post test data on visual acuity rate

\begin{tabular}{|c|c|c|c|c|c|c|c|}
\hline TEST & GROUP1 & GROUP2 & GROUP3 & df & SS & MOS & F value \\
\hline \multirow{2}{*}{ Pre } & \multirow{2}{*}{10.26} & \multirow{2}{*}{10.4} & \multirow[t]{2}{*}{9.93} & 2 & 1.73 & 0.86 & \multirow{2}{*}{$2.23^{*}$} \\
\hline & & & & 42 & 81.46 & 1.93 & \\
\hline \multirow{2}{*}{ Post } & \multirow{2}{*}{13.46} & \multirow{2}{*}{12.26} & \multirow[t]{2}{*}{10} & 2 & 92.97 & 46.48 & \multirow{2}{*}{$31.15^{*}$} \\
\hline & & & & 42 & 62.66 & 1.49 & \\
\hline \multirow[t]{2}{*}{ Adjusted } & \multirow[t]{2}{*}{13.47} & \multirow[t]{2}{*}{12.27} & \multirow[t]{2}{*}{9.98} & 2 & 92.81 & 46.40 & \multirow[t]{2}{*}{$30.48^{*}$} \\
\hline & & & & 41 & 62.42 & 1.52 & \\
\hline
\end{tabular}

\section{Significance at 0.05 level}

Table value required for significant at 0.05 level with df 2 and 42 and 2 and 41 are 3.22 and 3.23 respectively.

Table I shows that the adjusted post-test means values of Visual acuity rate for Manavalakalai Group, eye exercise Group and Control Group are 13.47, 12.27 and 9.98 respectively. The obtained F-ratio of 30.48 for adjusted posttest mean is much greater than the table value of 3.23 for $\mathrm{df} 2$ and 41 required for significant at .05 level of confidence.

The results of the study indicate that there are significant differences among the adjusted post-test means of Manavalakalai Group, eye exercise Group and Control Group on the Visual acuity rate.

To determine which of the paired means had a significant difference, the motion coherence threshold test was applied as Post hoc test and the results are presented in Table II.

Table II:-Scheffe's test for the variances between the adjusted post-test paired means on Visionary

\begin{tabular}{|c|r|r|r|r|}
\hline \multicolumn{3}{|c|}{ Groups } & \multirow{2}{*}{ Mean } & \multirow{2}{*}{ CD } \\
\hline Group1 & Group2 & Group3 & \\
\hline 13.47 & 12.27 & & $-1.19^{*}$ & $5.10^{*}$ \\
\hline 13.47 & & & 9.98 & $-3.48^{*}$ \\
\hline \\
\hline
\end{tabular}

\section{Significant at.05 level of confidence}

Table II shows that the adjusted post-test means differences on Manavalakalai Group and Eye exercise Group, Manavalakalai Group and Control Group, Eye exercise Group and Control Group are 1.19, 3.48 and 2.29 respectively. The value 5.10 which shows significant differences at .05 level of confidence.

It could be concluded from the results of the study that there is a significant difference in Visual acuity rate between the adjusted post-test means of Manavalakalai Group and Eye exercise Group, Manavalakalai Group and Control Group, Eye exercise Group and Control Group. However, the improvements of Visual acuity rate were significantly higher for Manavalakalai Group than Eye Exercise Group and Control Group.

It could be also concluded that Manavalakalai Group is better than Eye Exercise Group and Control Group in improving Visual acuity rate.

The mean and adjusted values of pre and posttest of Manavalakalai Group, Eye exercise Group and Control Group on Visual acuity rate are graphically represented in the Figure -I. 


\section{Figure I:-}

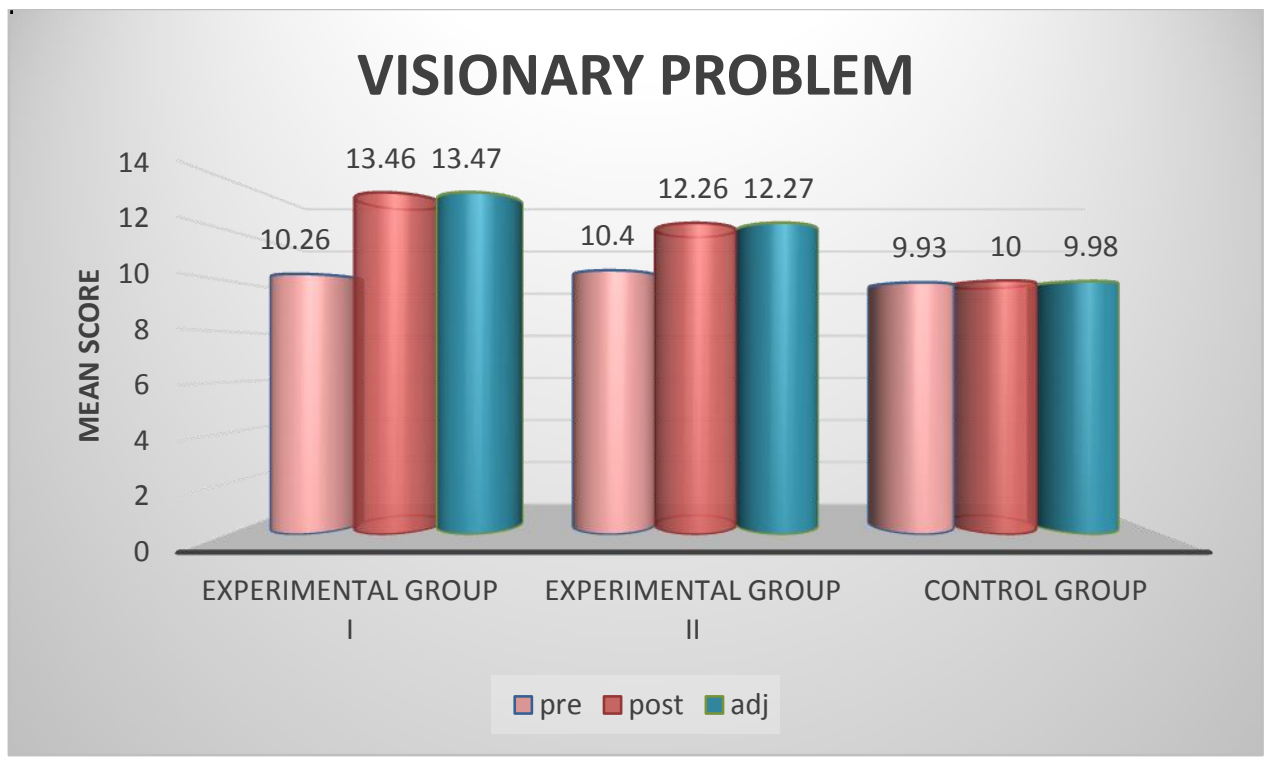

\section{Conclusions:-}

Based on the result of the study the following conclusions were drawn.

1. There was a significant difference between Manavalakalai group and eye exercise group when compared to the control group on physiological variables of vision (eyesight).

2. There was a significant improvement in eyesight and focusing ability level due to Manavalakalai and eye exercise when compared to the control group.

3. Manavalakalai was found to be better than the eye exercise group and control group in physiological variables of eyesight and vision improvement.

\section{Recommendations:}

1. A similar study may be conducted by selecting other Physiological variables as criterion variables.

2. A similar study may be conducted by selecting Performance related variables as criterion variables.

3. A similar study may be attempted by selecting other psychological variable for the subjects.

4. A similar study may be conducted for other female age group or male group as subjects.

5. Similar study may be undertaken to analyze the other Psychological and Hematological parameters.

\section{References:-}

1. Mascaro JS, (2012)," Compassion meditation enhances empathic accuracy and related neural activity.", Soc Cogn Affect Neurosci. 29

2. Mohan M,et.al. (1986) "Effect of yoga Type Breathing on Heart Rate And Cardiac Axis of Normal Subjects." Indian J Physiol Pharmacol. 30(4):PP.334-40

3. Murugesan R, et.al. (2000).” Effect of selected Yogic Practices on The Management of Hypertension.” Indian J Physiol Pharmacol. 44(2): PP.207-10 